\title{
Expression of Growth Hormone Secretagogue Receptor on Growth Hormone-releasing Hormone Neurons and Neuropeptide Y Neurons in the Arcuate Nucleus of Rat Hypothalamus
}

\author{
Asuka Mano-Otagiri and Tamotsu Shibasaki \\ Department of Physiology, Nippon Medical School
}

Ghrelin is an endogenous ligand for growth hormone secretagogue (GHS) receptor (GHSR) in stomach extract. GHSs and ghrelin stimulate growth hormone (GH) secretion and food intake. In the hypothalamus, GHSR mRNA is expressed in GH-releasing hormone (GHRH) neurons and neuropeptide Y (NPY) neurons of the arcuate nucleus, which are involved in the regulatory mechanism of GH secretion and feeding behavior, respectively. We performed double-labeled immunofluorescence for GHSR and GHRH or NPY to verify the presence of GHSR protein in GHRH and NPY neurons of the arcuate nucleus. GHSR protein was found in GHRH neurons in the ventral and lateral parts of the arcuate nucleus and in NPY neurons in the portion medial to that of the GHRH neurons. These results suggest that ghrelin/GHSR is involved in the regulatory mechanism of GH secretion and feeding behavior through GHRH and NPY neurons, respectively.
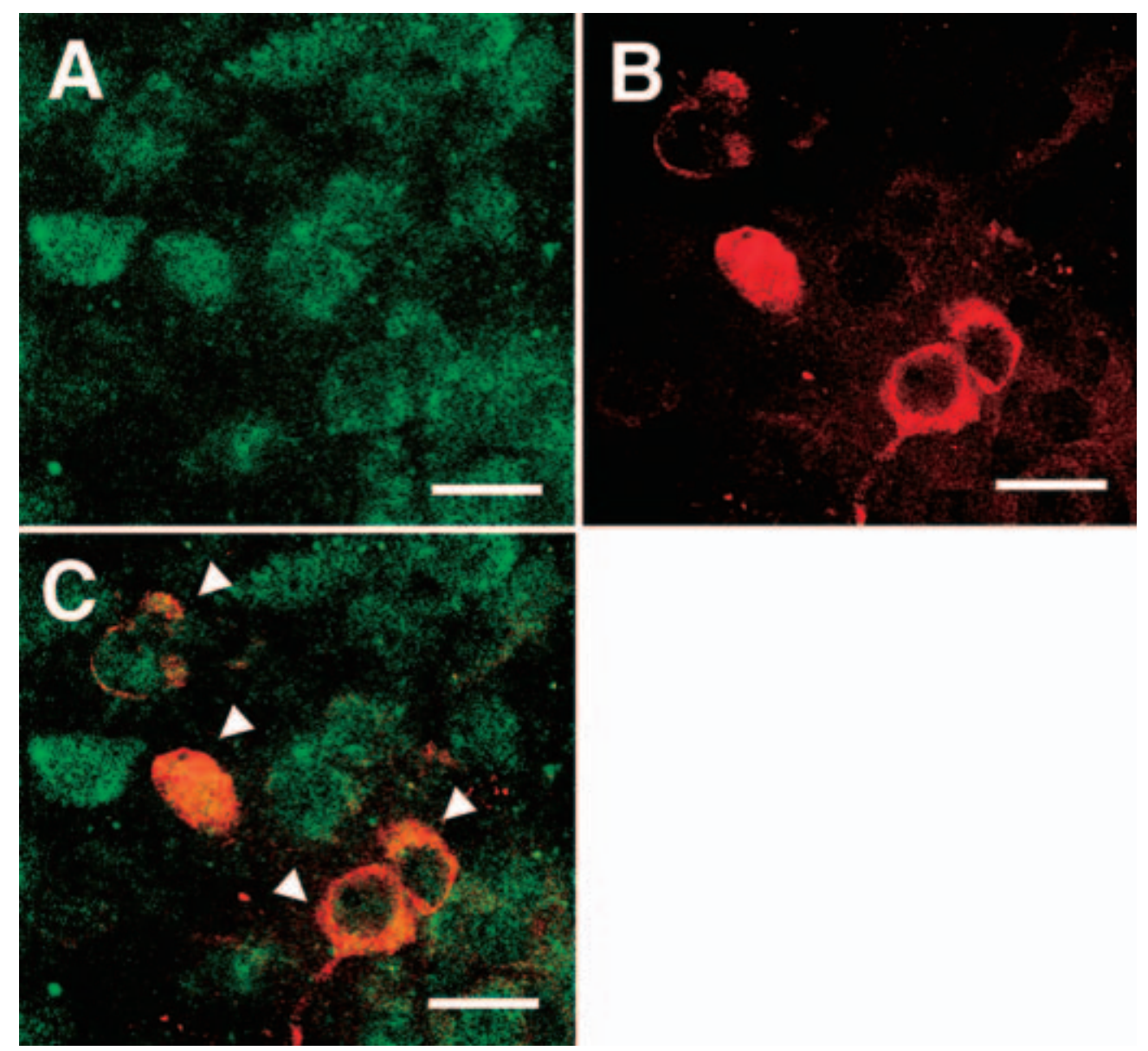

Fig. 1

Correspondence to Asuka Mano-Otagiri, Department of Physiology, Nippon Medical School, 1-1-5 Sendagi, Bunkyoku, Tokyo 113-8602, Japan 

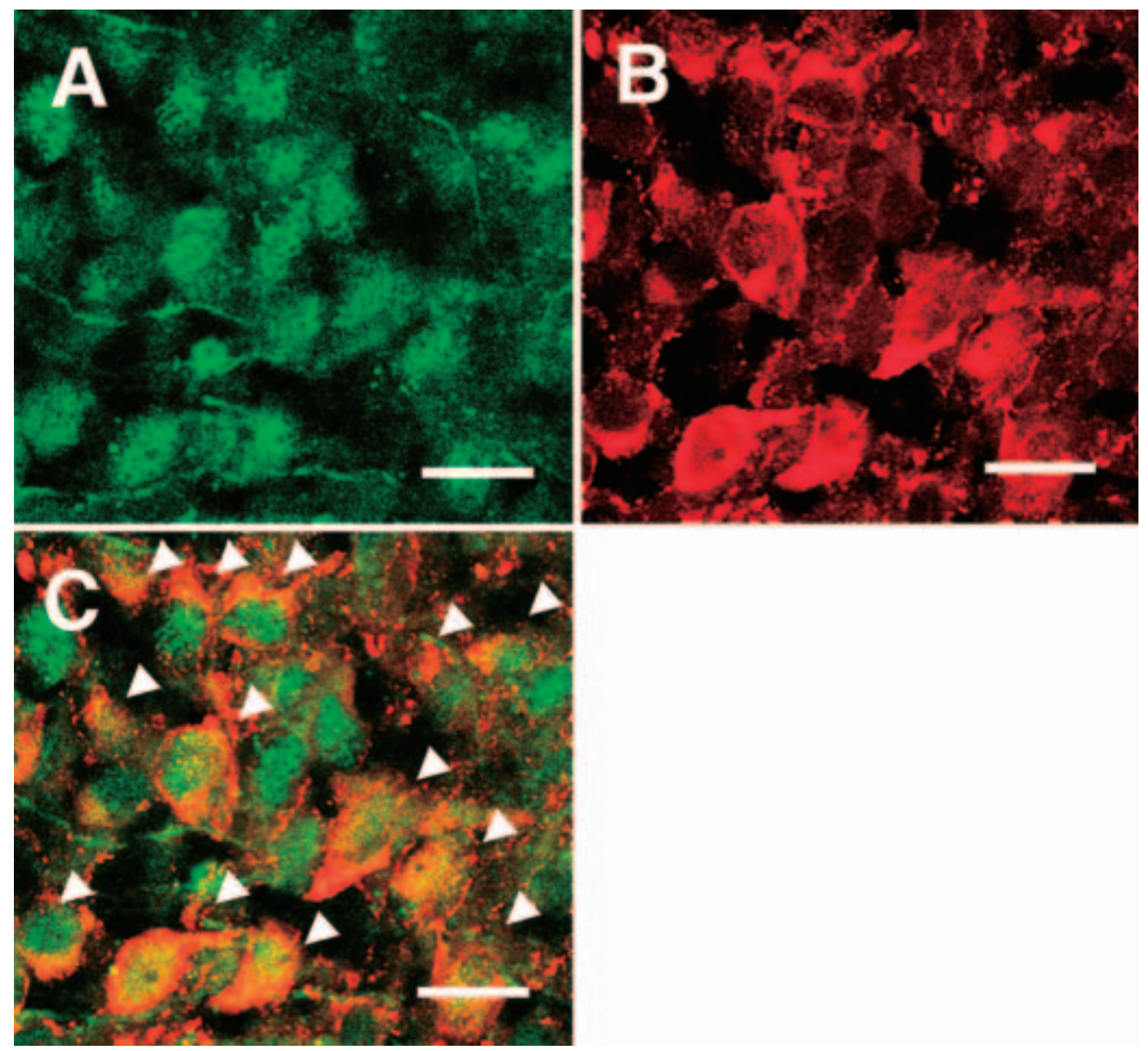

Fig. 2

Fig. 1 Double-labeled immunofluorescence of GHSR and GHRH in the arcuate nucleus of rat hypothalamus showing confocal images of GHSR (A), GHRH (B), and both (C). Arrows indicate GHSR-positive GHRH neurons. Scale bars, $50 \mu \mathrm{m}$.

Fig. 2 Double-labeled immunofluorescence of GHSR and NPY in the arcuate nucleus of rat hypothalamus showing confocal images of GHSR (A), NPY (B), and both (C). Arrows indicate GHSR-positive NPY neurons. Scale bars, $50 \mu \mathrm{m}$.

E-mail: asuka@nms.ac.jpＪournal Website (http://www.nms.ac.jp/jnms/) 